Document downloaded from:

http://hdl.handle.net/10251/31948

This paper must be cited as:

Bringas, E.; Köysüren, O.; Quach, DV.; Mahmoudi, M.; Aznar Gimeno, E.; Roehling, JD.; Marcos Martínez, MD.... (2012). Triggered release in lipid bilayer-capped mesoporous silica nanoparticles containing SPION using an alternating magnetic field. Chemical Communications. 48:5647-5649. doi:10.1039/C2CC31563G.

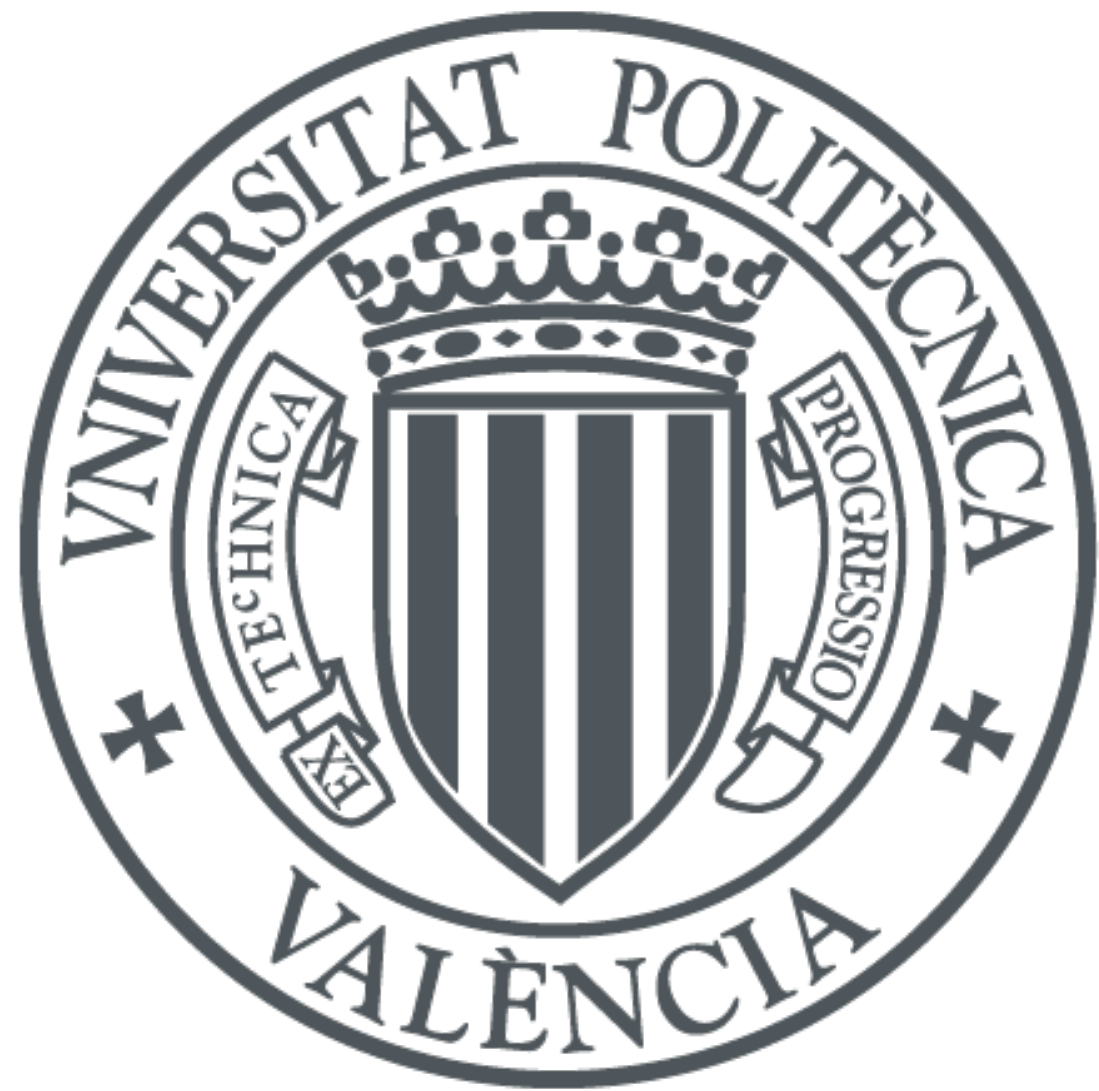

The final publication is available at

http://dx.doi.org/10.1039/C2CC31563G

Copyright Royal Society of Chemistry

Additional Information 


\title{
Triggered-release in Lipid Bilayer-Capped Mesoporous Silica Nanoparticles containing SPION using an Alternating Magnetic Field
}

\author{
Eugenio Bringas, ${ }^{* a, b}$ Özcan Köysüren, ${ }^{a, c}$ Dat V. Quach, ${ }^{a}$ Morteza Mahmoudi, ${ }^{d, e}$ Elena Aznar, ${ }^{f, g}$ John D. \\ Roehling, ${ }^{a}$ M. Dolores Marcos, ${ }^{g, h, f}$ Ramón Martínez-Máñez, ${ }^{* g, h, f}$ and Pieter Stroeve ${ }^{* a}$ \\ ${ }_{5}$ Received (in $\left.X X X, X X X\right)$ Xth $X X X X X X X X X 20 X X$, Accepted $X$ th $X X X X X X X X X 20 X X$ \\ DOI: $10.1039 / b 000000 x$
}

We report here the on-command cargo controlled delivery using an alternating magnetic field (AMF) from magnetic silica mesoporous supports capped with a lipid bilayer.

10 In recent years scientists have developed different kinds of drug delivery systems. In this field, the design of chemical and physical stimuli-responsive gated mesoporous materials have recently demonstrated to be an excellent approach for the development of smart nanodevices. In fact, the unique 15 characteristics of functionalized mesoporous silica supports such as high homogeneous porosity, inertness, robustness, thermal stability, the presence of tunable pore sizes, homogeneous pore distribution and high loading capacity, makes these scaffoldings ideal for hosting functional guest molecules. Additionally, the 20 possibility of incorporating in the external surface functional groups able to open or close at will or including capping molecules, provides advanced control release applications. One of the most captivating features of such systems is the possibility to prepare "zero release" devices that deliver entrapped guests 25 exclusively upon the application of an external stimulus. ${ }^{1}$ Chemical stimuli ${ }^{2}$ as redox molecules, selected anions, $\mathrm{pH}$ changes and biomolecules have been used to develop gated materials with controlled release features. In contrast to chemical, physical stimuli have the advantage of displaying cargo release 30 which can, in principle, be controlled spatially and temporally by fine-tuning the area and time where and when the stimuli is applied. Among different physical triggers, such as light $^{3}$ and temperature, ${ }^{4}$ the use of magnetic fields is captivating. Although some examples have been reported for magnetically guided 35 delivery, the use of magnetic fields to control the opening of gated mesoporous materials is a barely studied area. As far as we know only two examples have been reported. In the first one, Stoddart, Zink et al. used a material that combined zinc-doped iron oxide nanocrystals within mesoporous silica nanoparticles 40 that were capped with pseudorotaxanes. ${ }^{4 b}$ Upon application of an alternating magnetic field (AMF), the nanocrystals generated local internal heating, causing the dethread of the pseudorotaxanes and cargo release. The second example was described by Vallet et al. ${ }^{4 c}$ In their work, the authors 45 demonstrated that DNA/magnetic NP conjugates were able to cap the pores of silica particles upon hybridization of DNA strands. The application of an AMF resulted in pore uncapping due to DNA melting and the subsequent release of fluorescein.
Taking into account these concepts and being aware of the 50 promising features of silica mesoporous supports as containers and magnetic fields as triggers we focused our attention on the development of new tailor-made simple to prepare magneticresponsive gated mesoporous materials. The expected performance of the designed capped support, depicted in Scheme ${ }_{55} 1$, is based on the use mesoporous silica NPs (of ca. $100 \mathrm{~nm}$ ) loaded with a suitable reporter (i.e. the dye methylene blue) and containing superparamagnetic iron oxide nanocrystals (SPION). The NPs are then capped with a lipid bilayer. The presence of an AMF was expected to increase the lipid bilayer permeability 60 which might result in cargo release.

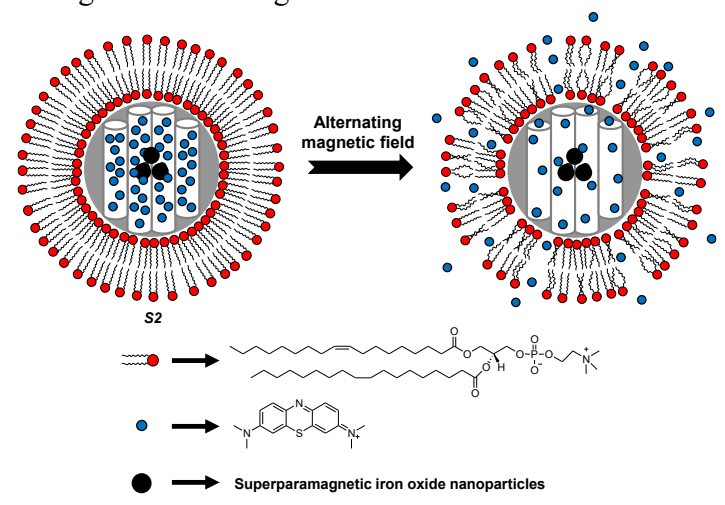

Scheme 1. Solid S2 expected performance.

In order to prepare the gated nanodevice, in a first step, SPION were synthesized following the procedure reported by Bruce et al.. ${ }^{5}$ Typical transmission electron microscopy (TEM) images of ${ }_{65}$ the prepared solid showed well defined NPs, whereas powder Xray diffraction (XRD) studies displayed the characteristic peaks of SPION. The average diameter of the synthesized SPION was estimated to be of ca. $18.6 \mathrm{~nm}$, using Scherrer's formula. ${ }^{6}$ Additionally, by vibrating sample magnetometer (VSM) analysis, 70 a magnetization saturation value of $52.8 \mathrm{emu} \mathrm{g}^{-1}$ was calculated for the prepared SPION (see Figure SI-6a for details).

In a second step, the magnetic mesoporous NPs (S1) were synthesized by hydrolysis of a silica precursor (TEOS) in a basic ferrofluid-CTAB solution. XRD patterns of S1 (Figure 1a) 75 showed the four low angle reflections distinctive of a mesoporous MCM-41-type material and characteristic reflections of SPION in the $28<2 \theta<68$ range. Moreover, representative scanning transmission electron microscope (STEM) micrograph depicted 
in Figure 1b showed the typical matrix of a mesoporous phase surrounding the superparamagnetic NPs.
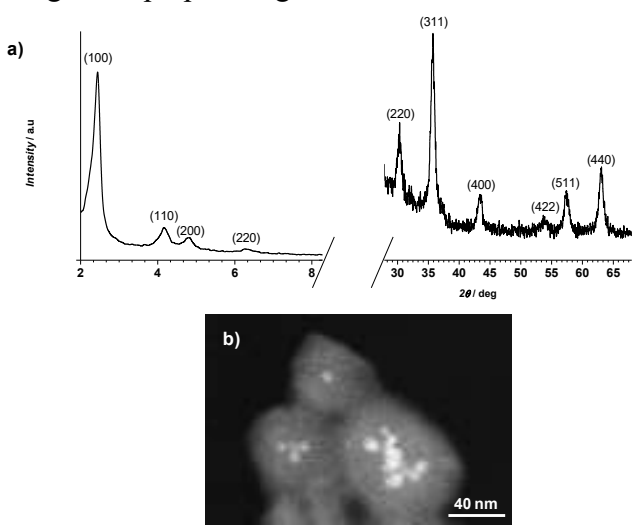

Figure 1. (a) Powder X-ray diffraction pattern of solid S1 from $2 \theta=2^{\circ}$ to $8^{\circ}$ showing the typical four low-angle reflections of the MCM-41

5 hexagonal array and, from $2 \theta=28^{\circ}$ to $68^{\circ}$ showing the reflections that can be indexed to the SPIONs cubic array. b) STEM image of S1 showing the typical porosity of the MCM-41 mesoporous matrix and the superparamagnetic particles.

From EDX analysis, the molar ratio between silicon and iron 10 in $\mathbf{S 1}$ was calculated to be $4.0 \pm 0.5$, this value being close to the theoretically expected $\mathrm{Si} / \mathrm{Fe}$ molar ratio of 5.0 employed in the reaction mixture used in the synthesis of the NPs. From VSM studies, a magnetization saturation of $14.0 \mathrm{emu} \mathrm{g}^{-1}$ was calculated for S1 (Figure 2). This lower magnetization value when 15 compared with SPION is coherent with the calculated silicon/iron ratio in the composite material S1. Moreover, despite this reduction in the magnetization behaviour, solid S1 still display excellent magnetic response and redispersibility.

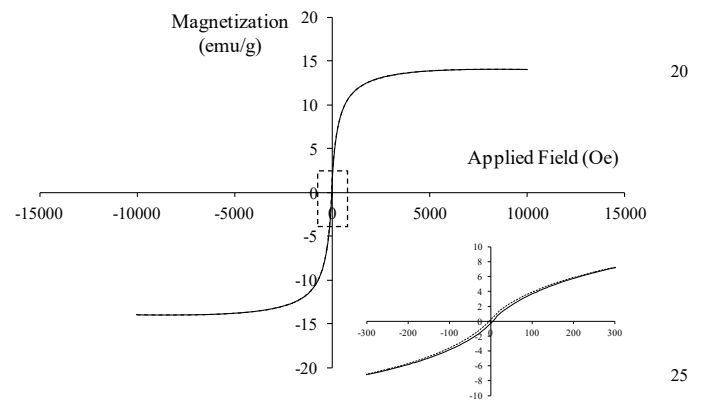

Figure 2. Magnetization curves of solid S1. The inset shows the expansion of the area marked by the dashed rectangle.

For the preparation of the gated material S2, solid S1 was dispersed in a solution of methylene blue in water and stirred for 3024 hours. Moreover, unilamellar lipid vesicles of 1,2-dioleoylsn-glycero-3-phosphocholine (DOPC) were obtained by evaporating a solution of the lipid in chloroform in a precleaned glass vial and further redispersion in phosphate buffer saline (PBS) $0.25 \mathrm{x}\left(\mathrm{pH}=7.4\right.$, phosphate concentration $2.5 \times 10^{-3} \mathrm{~mol} \mathrm{~L}^{-}$ $\left.{ }_{35}{ }^{1}\right) .^{7}$ Then, $100 \mu \mathrm{L}$ of the vesicle mixture was vigorously mixed with $25 \mu \mathrm{L}$ of a suspension of the loaded solid $\mathbf{S 1}(50 \mathrm{mg})$ in 5 $\mathrm{mL}$ of a saturated solution of methylene blue. The final solid $\mathbf{S 2}$ was obtained after several steps of centrifugation and washing with PBS $0.25 x$. Such final S2 mesoporous NP-supported lipid 40 bilayers are somehow similar to some recently reported systems ${ }^{8}$ which synergistically combine properties of liposomes and nanoporous particles.

The controlled release performance of $\mathbf{S 2}$ was evaluated via methylene blue delivery experiments in water in both, the 45 presence and the absence of an AMF. In a typical experiment, two different samples were prepared by dispersing $\mathbf{S 2}$ in water in the presence of PBS $(\mathrm{pH}=7.4)$. One batch was exposed to an AMF $(50 \mathrm{~Hz}, 1570 \mathrm{G})$ while the other was taken as control. To eliminate possible macroscopic thermal effects from the magnet, 50 samples exposed to an AMF were immersed in a water bath at $21 \pm 1{ }^{\circ} \mathrm{C}$ (Figure SI-2). After a fixed time, the corresponding suspensions were centrifuged and the released cargo was determined through the monitorization of the UV-vis absorbance band in the aqueous phase of the dye methylene blue at $655 \mathrm{~nm}$.

55

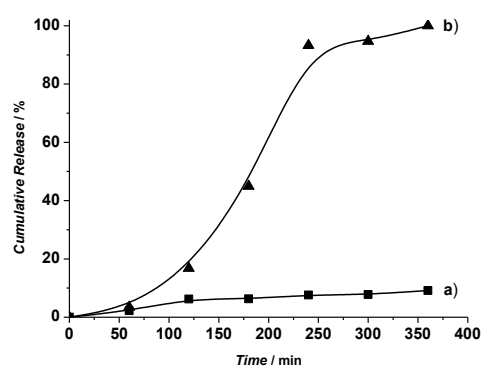

65 Figure 3. Cumulative release profile of methylene blue from solid S2 dispersed in PBS a) without AMF and b) in the presence of an AMF $(50 \mathrm{~Hz}, 1570 \mathrm{G})$. Release data were normalized to the maximum delivery obtained for solid S2 in the presence of the AMF.

The results (Figure 3) confirmed the fine tune triggering event; 70 i.e. whereas solid $\mathbf{S 2}$ displayed no release, the application of an AMF induced the release of the entrapped guest. A detailed study of the data indicated that more than $90 \%$ of the maximum deliverable methylene blue dye was released within the first 4 hours in samples exposed to AMF, whereas it was necessary to 75 wait for several weeks in order to observe a significant delivery of the dye from $\mathbf{S 2}$ in water in the absence of the magnetic field. Furthermore, to study the influence of temperature on the lipid bilayer permeability we carried out release experiments at 25 and $50{ }^{\circ} \mathrm{C}$ in the absence of an AMF (see Figure SI-7). We found a 80 massive delivery at $50{ }^{\circ} \mathrm{C}$ even at short times, while the release at $25{ }^{\circ} \mathrm{C}$ was negligible. Thus, the observed sustained delivery from S2 observed in the presence of an AMF is assigned to a combination of the lipid bilayer local warming and changes in its permeability promoted by the vibration of the NPs in the presence 85 of an AMF. ${ }^{9}$ Moreover, in order to additionally assess this magnetic triggering effect some further control experiments were carried out. A mesoporous material loaded with the methylene blue dye, capped with the lipid bilayer but lacking the presence of SPION (solid S3) was prepared. Suspensions of S3 in water ${ }_{90}$ displayed no release of the cargo either in the absence or in the presence of an AMF. This behaviour draws attention to the crucial role played by SPION in the gating mechanism.

Cell internalization of mesoporous silica NPs bearing gated stimuli-responsive scaffoldings is an appealing new 95 interdisciplinary research field on the frontier of nanoscience. One fundamental goal in this area is the understanding of the toxicity of these NPs at cellular level as a crucial factor for the rational design of nanomaterials for biomedical applications. Even being aware of the non-toxic nature of lipid bilayers, ${ }^{10}$ we 
tested capped S2 NPs at different concentrations for prospective cell viability assays using the MTT (3-(4,5-dimethylthiazol-2-yl)2,5-diphenyltetrazolium bromide) and XTT (sodium(2,3-bis(2methoxy-4-nitro-5-sulphophenyl)-2H-tetrazolium-5-

5 carboxanilide) method $^{11}$ in various human cell lines including human nervous (A172), liver (HEPG2), heart (HCM), lung (A549), kidney (293T), colon (SW480), brain (BE(2)-C) and skin (A431). According to the results depicted in Figure 4 and SI-8 to SI-11, cell viabilities in the presence of $\mathbf{S 2}$ were both cell-type10 and NP-concentration-dependent.

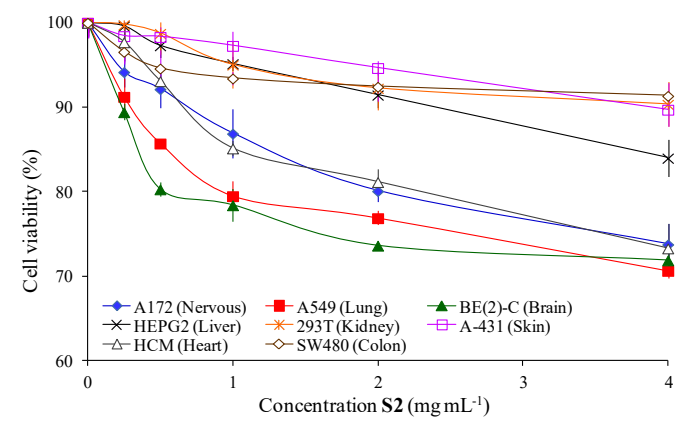

Figure 4. Cell viabilities resulted from MTT assay after 4 hours of treatment with different concentrations of solid $\mathbf{S 2}$.

As remarkable outcome, cellular toxicity of $\mathbf{S 2}$ at concentrations lower than $0.5 \mathrm{mg} \mathrm{mL}^{-1}$ was negligible for all the 15 cell lines under study, whereas at higher concentrations (from 1 to $4 \mathrm{mg} \mathrm{mL}^{-1}$ ) a trace of toxicity was observed for brain, nervous, lung, and heart human cell lines in agreement with the usually more sensitive behaviour of these cells to alien materials.

This preliminary study was completed treating human 20 erythromyeloblastoid leukemia suspension cells ${ }^{12}$ with $\mathbf{S 2}$ to obtain information about the effect of the NPs in the cell cycle. Solid S2 did not show detectable effects on the cell-life cycle of these cells, even at high applied dosage (i.e. $4 \mathrm{mg} \mathrm{mL}^{-1}$ ) (see Figure SI-12 (a-f)). In particular, there were no traces of 25 variations in apoptotic fraction ( $\mathrm{sub} \mathrm{G}_{0} \mathrm{G}_{1}$ stage), the $\mathrm{G}_{0} \mathrm{G}_{1}$ phase, $\mathrm{S}$ phase (i.e. DNA synthesis stage), and $\mathrm{G}_{2} \mathrm{M}$ phase areas before and after interaction with NPs.

In summary, we have reported here a new magneticallytriggered gated material in which cargo delivery can be remotely 30 activated by increasing lipid bilayer permeability thanks to the interaction of SPION in a silica mesoporous support with an AMF. The easy preparation of the gated material, the robustness and high loading capacity of the cargo reservoir, the wide range of possibilities that lipid bilayers have in relation to their 35 straightforward non-covalent modification with a variety of ligands, the biocompatibility displayed by the NPs in human cell lines, combined with the smart remote release activation using a friendly simple AMF make these new hybrid nanomaterials attractive systems for the future design of on command delivery 40 nanodevices in a wide range of applications.

Financial support from the Spanish Government (projects MAT2009-14564-C04-01 and CTQ2008-00690) and the Generalitat Valenciana (project PROMETEO/2009/016) is gratefully acknowledged. E.B thanks to the Spanish Ministry of ${ }_{45}$ Education (MEC) for his José Castillejo fellowship (JC20100090).

\section{Notes and references}

${ }^{a}$ Department of Chemical Engineering and Materials Science. University of California, Davis, California 95616, United States. Fax: (530) 75250 1031; E-mail: pstroeve@ucdavis.edu

${ }^{b}$ Department of Chemical Engineering and Inorganic Chemistry, ETSIIT. University of Cantabria. Avda. de los Castros s/n, 39005 Santander, Spain. Fax: (+34) 942201591; E-mail: eugenio.bringas@unican.es

${ }^{c}$ Department of Chemical Engineering. Selçuk University, Konya, 55 42031, Turkey.

${ }^{d}$ Nanotechnology Research Center. Faculty of Pharmacy. Tehran

University of Medical Sciences. Tehran, Iran.

${ }^{e}$ National Cell Bank, Pasteur Institute of Iran, Tehran, Iran.

${ }^{f}$ CIBER de Bioingeniería, Biomateriales y Nanomedicina (CIBER-BBN).

${ }_{60}{ }^{g}$ Centro de Reconocimiento Molecular y Desarrollo Tecnológico (IDM).

Unidad Mixta Universitat Politècnica de València-Universitat de

València. Valencia, Spain. Fax: (+34) 963879349; E-mail:

rmaez@qim.upv.es

${ }^{h}$ Departamento de Química. Universitat Politècnica de València. Camino 65 de Vera s/n, 46022, Valencia, Spain.

$\dagger$ Electronic Supplementary Information (ESI) available: [Experimental details. S1 and S2 characterization. Biological studies. Complete ref 8c.]. See DOI: $10.1039 / \mathrm{b} 000000 \mathrm{x} /$

1 a) E. Aznar, R. Martínez-Máñez, F. Sancenón, Expert Opin. Drug

70 Deliv. 2009, 6, 643; b) K. Cotí, M. E. Belowich, M. Liong, M. W. Ambrogio, Y. A. Lau, H. A. Khatib, J. I. Zink, N. M. Khashab, J. F. Stoddart, Nanoscale, 2009, 1, 16.

2 See for example: a) C.-Y Lai, B.G. Trewyn, D.M. Jeftinija, K. Jeftinija, S. Xu, S. Jeftinija, V. S. -Y. Lin, J. Am. Chem. Soc. 2003,

75125,$4451 ;$ b) C. Park, K. Oh, S.C. Lee, C. Kim, Angew. Chem. Int. Ed. 2007, 46, 1455; c) R. Casasús, E. Climent, M.D. Marcos, R. Martínez-Máñez, F. Sancenón, J. Soto, P. Amorós, J. Cano, E. Ruiz, J. Am. Chem. Soc. 2008, 130, 1903; d) R. Liu, P. Liao, J. Liu, P. Feng, P. Langmuir 2011, 27, 3095; e) E. Climent, R. MartínezMáñez, F. Sancenón, M. D. Marcos, J. Soto, A. Maquieira, P. Amorós, Angew. Chem. Int. Ed. 2010, 49, 7281.

3 a) N. K. Mal, M. Fujiwara, Y. Tanaka, Nature 2003, 421, 350; b) E. Aznar, M.D. Marcos, R. Martínez-Máñez, F. Sancenón, J. Soto, P. Amorós, C. Guillem, J. Am. Chem. Soc. 2009, 131, 6833.

${ }_{85} 4$ a) Q. Fu, G. V. R. Rao, L. K. Ista, Y. Wu, B. P. Andrzejewski, L. A. Sklar, T. L. Ward, G. P. López, Adv. Mater. 2003, 15, 1262; b) C.R. Thomas, D.P. Ferris, J.-H. Lee, E. Choi, M.H. Cho, E.S. Kim, J.F. Stoddart, J.-S. Shin, J. Cheon, J.I. Zink, J. Am. Chem. Soc. 2010, 132, 10623; c) E. Ruiz-Hernández, A. Baeza, M. ValletRegí, ACSNano 2011, 5, 1259; d) E. Aznar, L. Mondragón, J.V. Ros-Lis, F. Sancenón, M.D. Marcos, R. Martínez-Máñez, J. Soto, E. Pérez-Payá, P. Amorós, Angew. Chem. Int. Ed. 2011, 50, 11172.

5 I.J. Bruce, J. Taylor, M. Todd, M.J. Davies, E. Borioni, C. Sangregorio, T. Sen, J. Magnet. Magnet. Mater. 2010, 284, 145.

956 T. Sen, G. Magdassi, G. Nizri, I.J. Bruce, Micro \& Nano Letters 2006, 1, 39.

7 L. Zhang, M.L. Longo, P. Stroeve, P. Langmuir 2000, 16, 5093.

8 a) J. Liu, A. Stace-Naughton, X. Jiang, C.J. Brinker, J. Am. Chem. Soc. 2009, 131, 1354; b) J. Liu, X. Jiang, C. Ashley, C.J. Brinker, $100 \quad$ J. Am. Chem. Soc. 2009, 131, 7567; c) C.E. Ashley et al. Nature Materials 2011, 10, 389.

9 See for example: a) T. Hoare, B.P. Timko, J. Santamaría, G.F. Goya, S. Irusta, S. Lau, C.F. Stefanescu, D. Lin, R. Langer, D.S. Kohane, Nano Lett. 2011, 11, 1395; c) S. Nappini, M. Bonini, F.B. 105 Bombelli, F. Pineider, C. Sangregorio, P. Baglioni, B. Norden, Soft. Matter. 2011, 7, 1025 .

10 Y. Malam, M. Loizidou, A.M. Seifalian, Trends Pharmacol. Sci. 2009, 30, 592.

11 M. Mahmoudi, S. Laurent, M.A. Shokrgozar, M. Hosseinkhani, 110 ACS Nano, 2011, 5, 7263.

12 M. Mahmoudi, K. Azadmanesh, M.A. Shokrgozar, W.S. Journeay, S. Laurent, Chem. Rev. 2011, 111, 3407. 